\title{
DEMOCRACIA E INTEGRACIÓN POLÍTICA. ¿CÓMO AFECTAN LOS PROCESOS DE INTEGRACIÓN A LA REPRESENTACIÓN POLÍTICA?
}

\author{
Carmen Innerarity \\ Universidad Pública de Navarra \\ E-mail: carmeni@unavarra.es
}

\begin{abstract}
RESUMEN
El artículo analiza cómo el actual debilitamiento de las fronteras estatales afecta al régimen democrático y, de manera especial, a la representación política, en su doble dimensión de canalización de demandas y de responsabilidad ante los ciudadanos. De modo concreto, expone en qué consiste el denominado «déficit democrático» del proceso de integración de Europa. Finalmente, ofrece una visión crítica de las distintas propuestas realizadas desde la Sociología y la Ciencia Política para superar las carencias democráticas de dicho proceso.
\end{abstract}

En el curso de los últimos cuatro siglos el Estado ha venido siendo el lugar en el que se configuraba la identidad social y política de las personas por medio de la pertenencia a una nación. El Estado nacional ha sido en la modernidad el escenario decisivo para la acción colectiva en la política interior y exterior, el actor privilegiado de las relaciones de poder.

Sin embargo, actualmente asistimos a una serie de transformaciones sociales y políticas que amenazan al Estado nacional de una manera mucho más radical que los movimientos obreros del siglo XIX. Estos exigían más prestaciones por parte del Estado y la ampliación de las posibilidades de participación en las instituciones estatales; es decir, eran demandas dentro del propio Estado,

\section{Reis}


que no afectaban a su permanencia como forma de organización política. En cambio, lo que se cuestiona en la actualidad es la vigencia de la propia institución estatal: si el Estado nacional surgió en un momento histórico concreto y como respuesta a unas circunstancias sociales, económicas, culturales y políticas determinadas, no parece tan descabellada la posibilidad de su desaparición una vez que han cambiado las circunstancias. No es posible absolutizar la alianza histórica de Estado, comunidad nacional, sistema económico y democracia parlamentaria como una situación necesaria e insuperable. Porque la globalización no significa sólo internacionalización económica. Inaugura una concepción desterritorializada de la política, un mundo en el que lo político ha adquirido una significación fuera de los marcos estatalmente determinados.

El objeto de estas páginas es exponer los problemas que para la democracia, y especialmente para la representación política, se derivan del actual debilitamiento de las fronteras. Como ejemplo concreto me referiré el proceso de integración europea. Asimismo, expondré las principales propuestas realizadas desde distintos sectores de la ciencia política para articular la representación política en esta «tercera transformación» de la democracia (Dahl, 1989: 320)ํ․

\section{DEL ESTADO NACIONAL A LA DESTERRITORIALIZACIÓN DE LA POLÍTICA}

Si el Estado nacional pudo imponerse en toda Europa como modelo de organización política y desde aquí exportarse al resto del mundo, fue gracias a su capacidad para adaptarse a las circunstancias de modernización social, cultural y, sobre todo, económica. La soberanía del Estado hacia dentro permitía la realización de un orden jurídico interno garantizado ahora por el propio Estado, la soberanía hacia fuera implicaba la capacidad de autoafirmarse en la competencia entre los distintos Estados.

Aún más importante para el proceso de modernización resultaba la separación del Estado de la sociedad civil, es decir, la diferenciación específica del aparato estatal. El Estado se limita a la dirección política y a funciones administrativas, mientras que deja a la sociedad el desempeño de actividades productivas que hasta entonces estaban bajo el dominio de la política. Con ello se hace posible el desarrollo de una economía de mercado diferenciada del Estado. Esta separación entre política y economía se refleja en la distinción dentro del ordenamiento jurídico entre Derecho público y Derecho privado, que permite la aparición de un ámbito de autonomía individual para el ciudadano, que hará posible el desarrollo de los derechos civiles individuales.

Además de favorecer el proceso de modernización, la aportación del Estado

1 Para Robert Dahl las distintas transformaciones se han derivado de las diferentes formas de organización política en las que se ha configurado la democracia: la ciudad-estado griega y el Estado nacional (Dahl, 1994). 
nacional consistió en haber solucionado a un tiempo dos problemas que se plantean en el momento de su aparición: sobre la base de un nuevo modo de legitimación hace posible una nueva forma de integración social (Habermas, 1996: 135). Por un lado, el poder secularizado debía buscar nuevas fuentes de legitimación. Y, por otro, la integración social resultaba problemática por la urbanización, la modernización económica y la extensión y aceleración del tráfico de personas, mercancías y noticias. El Estado nacional responde a ambas exigencias con una movilización politica de sus ciudadanos. La naciente conciencia nacional hizo posible unir una forma abstracta de integración social con nuevas estructuras de decisión política. La extensión de la posibilidad de participar en la política creó, junto con el estatus de ciudadano, un nuevo plano de solidaridad regido por el Derecho. Al mismo tiempo abrió al poder político una nueva fuente de legitimación secularizada. De este modo, los ciudadanos en sentido cultural pasaron a ser ciudadanos en sentido jurídico-político. La ciudadanía en el primer sentido significaba fundamentalmente la condición de miembro de una comunidad política. Con la separación entre Estado y sociedad y la extensión de la soberanía a todo el pueblo, los derechos de los individuos, protegidos de una manera paternalista por sus señores, pasan a ser derechos de la persona y del ciudadano garantizados por el Estado. Al consenso jurídico se le añade la vitalidad del sentimiento de copertenencia, de identidad colectiva. La idea de nación proporciona un contenido cultural a la realidad jurídica del Estado y constituye, así, una nueva fuente de integración.

La política se enfrenta en la actualidad a un contexto semejante, de enormes cambios políticos, económicos, sociales y culturales. En el fondo son circunstancias que plantean la misma situación que en el momento en que surge el Estado nacional, y es, como se verá, la exigencia de nuevas formas de legitimación y de integración que sean acordes con los principios democráticos. $Y$ ésta es una fuente de incertidumbre para el futuro de la política, cuando "privados de las certidumbres de la era de los estados-naciones — cuando el cuerpo social era algo dado, la herencia sobre la cual podían edificarse toda clase de construcciones políticas - carecemos de una receta cómoda para delimitar el espacio de nuestras solidaridades» (Guéhenno, 1995: 62).

Las funciones tradicionales del Estado han sufrido una gran transformación como consecuencia de profundos cambios, en virtud de los cuales no es exagerado afirmar que la política ha dejado de estar monopolizada por las instituciones estatales. Entre las causas fundamentales a las que se debe esta erosión de la función tradicional del Estado suele apuntarse el fenómeno de la globalización. Por supuesto que no se trata de un asunto completamente nuevo. Los intercambios económicos, la comunicación científica y los estilos culturales han atravesado siempre los límites de los Estados nacionales. Pero puede decirse que, pese a la irregularidad que estos fenómenos representaban para la lógica de la soberanía, el Estado nacional consiguió mantenerse como el eje de la vida social. Mientras que en el Estado nacional el ejercicio de la autoridad pública en diferentes ámbitos funcionales es coincidente con un territo- 
rio determinado, la situación actual apunta a lo que Schmitter ha calificado como una «creciente disociación entre circunscripciones territoriales y competencias funcionales» (Schmitter, 1996).

Desde la sociología se ha llamado "teoría de la sociedad como container» (Beck, 1994) o "nacionalismo metodológico» (Smith, 1979) a la idea de que los contornos de la sociedad hayan de coincidir con los del Estado nacional. Ésta es, de hecho, la coherencia pretendida por los Estados nacionales: espacios estatalmente delimitados y controlados se convierten en unidades de soberanía y seguridad territorial; se produce la homogeneidad cultural mediante la contraposición organizada; la soberanía es pensada y practicada de manera exclusiva. En la concepción territorial de la política, la cultura y el Estado las diferencias son esencializadas. Toda sociedad representa una unidad claramente delimitada. Sus límites coinciden con los del Estado y con los de un bloque cultural. El espacio en que se realizan las relaciones de intercambio y acción social no puede ser mucho mayor que el espacio alcanzado por las regulaciones políticas. En la medida en que las actividades económicas, las comunicaciones, la contaminación del medio ambiente, la producción y el consumo cultural se realizan dentro de los límites estatales, pueden ser gobernadas por el Estado.

Mientras esta congruencia se mantiene, la capacidad de gobierno y la legitimación del Estado se conservan intactas. Ahora bien, esto es precisamente lo que ahora se disuelve. La sociedad global que se ha ido configurando erosiona el Estado nacional en la medida en que sus límites territoriales son atravesados por una pluralidad de círculos sociales, redes de comunicación, relaciones mercantiles y mundos vitales. Si la sociedad se caracteriza por la diferenciación funcional, es difícil imaginarse que los sistemas funcionales (medios de comunicación, sistema financiero, ciencia, política...) converjan en unos mismos límites territoriales. La globalización suprime precisamente la coincidencia de los espacios económicos y políticos, lo que limita la eficacia del gobierno y la soberanía de las instituciones estatales. El Estado ya no es un principio de organización dominante, sino parte de un sistema de varios niveles, cada uno de los cuales no puede funcionar sin los otros y en el que las relaciones reticulares son más importantes que las jerárquicas. No es que carezca de sentido que un gobierno formule unas directrices de política económica, lo que ocurre es que esas directrices ya no pueden ser establecidas sin tener en cuenta lo que ocurre en otros lugares y lo decidido en otras instancias.

En estas circunstancias adquiere una gran fuerza el supuesto de que el debilitamiento de las fronteras significa también una disminución de las posibilidades de influir en los procesos políticos. No se trata sólo de que determinados actores o procesos escapen de hecho al control político, sino, sobre todo, que ya no es posible influir en los procesos políticos o, en todo caso, con un coste muy elevado. ¿Significa esta situación el "fin de la democracia» (Guehenno, 1995), en unas circunstancias en las cuales quedan difuminados dos de sus elementos fundamentales: la responsabilidad y el control políticos? Históricamente ha habido una alianza entre democracia y Estado nacional: la democra- 
cia se ha desarrollado en el Estado nacional y el Estado nacional ha encontrado en la democracia su forma política más moderna. Por ello, parece que el debilitamiento del Estado podría tener como consecuencia lógica el debilitamiento de la democracia. De hecho, el proceso de integración europea, como la cristalización en el ámbito europeo de la disolución progresiva de las fronteras estatales, ha sido acusado de adolecer de un «déficit democrático».

\section{2. ¿EN QUÉ CONSISTE EL «DÉFICIT DEMOCRÁTICO»?}

Con el proceso de integración europea ha surgido un orden político que establece nuevas competencias y regula nuevos procedimientos de decisión de carácter vinculante para hacer frente a la globalización, sin haber creado con ello un nuevo Estado y tampoco parece que lo vaya a hacer a corto o medio plazo. Este contexto, marcado por la pluralidad de instituciones y ámbitos de competencia, ha planteado con especial fuerza el interrogante acerca de las consecuencias que de aquí se derivan para la articulación de un gobierno que sea, al mismo tiempo, democrático y eficaz.

Si se toma como punto de referencia la democracia representativa, podemos afirmar que la política de la integración europea y las instituciones con ella creadas han sufrido una "carencia democrática». Esta carencia alude, en primer lugar, al hecho de que son los ejecutivos de los Estados miembros los actores principales, mientras que el papel de los parlamentos nacionales en la política europea, tanto en su construcción como en su desarrollo actual, es poco relevante. Las relaciones internacionales durante el predominio del Estado nacional exigían un cierto grado de independencia del poder ejecutivo respecto al parlamento nacional, que dejara un amplio margen para la negociación y, por tanto, para poder llegar a acuerdos con los demás paises. Precisamente el éxito del proceso de integración europea se debe, en gran medida, a una política dominada por los ejecutivos de los diferentes Estados nacionales.

Pero la constitución en 1979 del primer parlamento a nivel europeo elegido directamente supone un cambio fundamental en la política europea; cambio que será consumado cuando a partir del Acta Única de 1985 la lógica comunitaria sustituya a la lógica intergubernamental. Si la Unión Europea consistiera en una cooperación entre los gobiernos de los diferentes Estados no se plantearía el problema de su democraticidad. Serían los gobiernos de cada uno de los Estados, democráticamente legitimados, quienes exigirían responsabilidades a los actores de la estructura supraestatal. Pero la Unión Europea va a ser algo más que una forma de cooperación entre Estados, cada uno de ellos con sus propias instituciones soberanas. Ahora aparece ya una cierta organización política de carácter supraestatal con instituciones propias dotadas de poder político. A partir de entonces se pueden observar una serie de carencias fundamentales en el gobierno comunitario, juzgado desde la perspectiva de los principios democráticos. Ese «déficit democrático» alude a dos tipos de limita- 
ciones. Algunas de ellas unidas a arreglos institucionales (división de poderes insuficiente, falta de transparencia en las decisiones, debilidad de los mecanismos de control entre las instituciones) y otras de carácter más general, derivadas de la supuesta inexistencia de uno de los elementos considerados como requisitos para la instauración de un régimen democrático (Dahl, 1989): un demos común.

\section{2.a) La transformación de la soberania y la legitimidad de la politica europea}

Uno de los elementos definitorios del Estado moderno era la consideración de la soberanía como algo indivisible, no limitada más que por los derechos de los individuos que vivían en ese Estado, y estrechamente ligada a un territorio: el poder coercitivo que reside en el Estado abarca a los individuos que viven dentro de unas determinadas fronteras geográficas. Sin embargo, las transformaciones actuales del Estado afectan de una manera esencial a la noción de soberanía. En primer lugar, ésta ya no puede ser considerada como monopolio del Estado territorialmente definido, sino que el estado la comparte con otro tipo de estructuras supra o subestatales, e incluso con organizaciones que no poseen un carácter estrictamente político, como puede ser el Fondo Monetario Internacional. Estas entidades con las que el estado comparte ahora la soberanía imponen "constreñimientos decisorios» (Markoff, 1998: 36) al poder estatal. El poder político no descansa ya, entonces, de una manera exclusiva sobre la soberanía del Estado nacional, sino que la estatalidad es sustituida por la interdependencia, por el entrecruzamiento de competencias.

Por ello, la idea tradicional de soberanía nacional como monopolio exclusivo del poder político en un territorio es ahora mismo una ficción. Está siendo dustituida por una idea inclusiva de la soberanía. Hay modos de distinción exclusivos e inclusivos. Los primeros refieren alternativas, o esto o aquello. Proyectan una imagen del mundo como compuesto de elementos que se yuxtaponen sin confusión, en los que se excluyen identidades y pertenencias. Las distinciones inclusivas, en cambio, proyectan una idea completamente diferente de lo que debe entenderse por orden.

Esta propiedad se comprende desde la siguiente paradoja de la soberanía: en la era de la globalidad la soberanía estatal sólo es posible mediante la entrega de soberanía estatal. Los sujetos políticos aumentan su espacio de juego en la medida en que consiguen aumentar su riqueza cooperativa. El concepto de soberanía entendida como el ejercicio ilimitado, incompartible y exclusivo del poder público está siendo sustituido por el reconocimiento del hecho de que la soberanía está repartida entre diversas instituciones — de carácter local, regional, nacional, estatal e internacional-y limitada por esa pluralidad. En consecuencia, la soberanía debe ser entendida «menos como un límite definido territorialmente que como recurso para una política caracterizada por un entramado complejo transnacional»(Keohane, 1995). Esto no quiere decir que las 
fronteras no tengan un significado político o simbólico, sino que se ha vuelto tremendamente problemática su consideración como el principal medio de delimitación espacial.

La superioridad y el monopolio del Estado como centro de decisión política cada vez resulta más cuestionada de hecho hacia adentro por el creciente pluralismo cultural y político; hacia afuera, por las relaciones transnacionales, que van en aumento. Un pensamiento político adecuado a esta realidad deberá considerar las decisiones políticas no como actos supremos de soberanía del Estado, sino como resultado de contextos transnacionales de interacción social y política, y explicar la política democrática no como un sistema estatal de regulación de conflictos, sino como un proceso dinámico de interacción entre una pluralidad de fuerzas. El paradigma formal de las instituciones en torno al Estado debe ser ampliado con la inclusión de estructuras y procesos informales. Una categoría adecuada para ello es la de «redes políticas», como estructuras de interacción y comunicación entre los distintos actores. Bajo la perspectiva de las redes políticas, los procesos de decisión no son competencia exclusiva del parlamento, del gobierno o de la administración, sino que están determinados por una pluralidad de actores formales e informales.

Pero esta transformación de la soberanía no deja inalterada la democraticidad del sistema. La soberanía en un régimen democrático está vinculada con la responsabilidad política (accountability). La responsabilidad del gobierno ante los ciudadanos es la otra cara de la soberanía estatal en una democracia, si aceptamos la definición de democracia propuesta por Schmitter y Karl (1991), como el régimen o sistema de gobierno en el que los gobernantes son responsables de sus acciones en el terreno público ante los ciudadanos. La responsabilidad implica una serie de instituciones, como puede ser el parlamento o la celebración periódica de elecciones competitivas, que permitan a los ciudadanos ejercer un control sobre el gobierno. La responsabilidad, y el consiguiente control por parte de los ciudadanos, tiene, a su vez, dos dimensiones. Un gobierno es responsable cuando es representativo, es decir, cuando es receptivo con las demandas de los ciudadanos y las tiene en cuenta a la hora de tomar decisiones, cuando los ciudadanos disponen de la capacidad efectiva para influir en las decisiones políticas. Pero esto no es suficiente. Para que un gobierno sea responsable es imprescindible que sea también eficaz, es decir, que llegue a tomar decisiones que permitan satisfacer las demandas de los ciudadanos (Dahl). No basta con representar, es preciso gobernar. Con el fin de lograr la unidad necesaria para tomar decisiones que permitan gobernar, será preciso, en la mayor parte de los casos, llevar a cabo una serie de negociaciones en las que haya que actuar según la lógica de la "compensación recíproca diferida" (Sartori), es decir, ceder hoy en un punto para que la otra parte ceda mañana en otro. Y esto implica muchas veces un cierto "debilitamiento" de los vínculos con los ciudadanos, con el fin de llegar al consenso necesario para actuar. Éste es el sentido de la sustitución del mandato imperativo por el mandato representativo en los parlamentos modernos. 
Ambas dimensiones de la responsabilidad política — que podríamos denominar, respectivamente, representatividad y eficacia - se ven alteradas en la situación actual de integración política en Europa. Por un lado, la representatividad no queda asegurada, desde el momento en que no existen mecanismos institucionales que garanticen un control suficiente ni entre las instituciones ni de los ciudadanos respecto a las instituciones cuyas decisiones afectan a sus vidas. Las posibilidades de un control efectivo del Parlamento a la Comisión, que hace las veces de poder ejecutivo, son muy limitadas. Además de que ninguna moción de censura ha prosperado, aunque la última trajera como consecuencia la dimisión de la Comisión, la moción de censura no alcanza al Consejo, que es el principal responsable de las decisiones comunitarias. También son insuficientes las posibilidades de control mediante las elecciones europeas. Las elecciones al Parlamento Europeo no conducen a la formación de gobierno, porque el Parlamento no elige a la Comisión. Prevalece la designación por los gobernantes nacionales según cuotas fijas. El Parlamento únicamente tiene la facultad de ratificar o rechazar a los candidatos propuestos por el Consejo. Además, no vota a los candidatos individualmente, sino al conjunto de la Comisión.

Su función legislativa queda también bastante mermada, puesto que no tiene capacidad de iniciativa. Únicamente colegisla con el Consejo, a propuesta de la Comisión, sin ejercer, en consecuencia, los mismos poderes que un Parlamento nacional. Aunque su poder ha ido aumentando a partir del Acta Única Europea hasta el Tratado de Amsterdam, solamente tiene capacidad de codecisión junto con el Consejo de Ministros.

Por eso, fundamentalmente, el Parlamento Europeo no ha alcanzado el estatus de una institución representativa del pueblo, a pesar de ser la institución que surge del sufragio universal directo. A ello contribuye la inexistencia de un sistema electoral común y un sistema de partidos a nivel europeo que pudiera articular la competencia política, presentando programas y candidatos en todas las circunscripciones. Es cierto que, una vez celebradas las elecciones, los parlamentarios electos se unen en grupos según familias ideológicas bajo siglas supranacionales. Pero los candidatos a eurodiputados no son designados ni remunerados por partidos europeos. Por ello, son grupos con muy poca cohesión interna, entre otras razones porque la identificación ideológica se cruza con la estatal, primando esta última cuando lo que se discute afecta directamente a los intereses de uno de los Estados miembros.

Por otra parte, en las elecciones legislativas dentro del ámbito estatal, los temas europeos no desempeñan un papel muy importante, sino que la rivalidad interpartidista se desarrolla sobre todo a nivel intraestatal, es decir, en torno a cuestiones de política nacional ${ }^{2}$. De hecho, el programa europeo de los partidos suele ser de menor extensión que el que se refiere a la política nacional, autonómica o municipal. Se pone aquí de manifiesto la poca impor-

2 Sobre este punto, ver Canal e Innerarity (2000). 
tancia concedida por los partidos a las instituciones europeas, a partir de la conciencia de que no es la competencia partidista la que rige la formación del gobierno europeo. Muestra de ello es también que en la campaña generalmente los partidos no suelen hacer referencia a la actividad de los candidatos en el Parlamento Europeo; aluden, en todo caso, a su experiencia en la Comisión ${ }^{3}$.

Como consecuencia de la percepción del Parlamento como una institución limitada en sus funciones y poco representativa, no se concede demasiado valor a la participación en los comicios europeos. Pertenecen al grupo de las llamadas «elecciones de segundo orden» (Reif, 1985). De hecho, el índice de participación es, generalmente, menor que en otro tipo de convocatorias ${ }^{4}$.

El peso en el reparto de los poderes está orientado, por tanto, hacia las instituciones que representan a los gobiernos de los Estados miembros. El Parlamento, representación no de los gobiernos sino de la ciudadanía, ocupa un lugar marginal y no dispone esencialmente más que de un poder consultivo y un poder de control bastante limitado.

También la dimensión de la responsabilidad que se refiere a la eficacia del gobierno queda alterada. La teoría empírica de la democracia señala una serie de requisitos institucionales que refuerzan la posibilidad de pedir cuentas al gobierno sobre su gestión en términos de eficacia. Uno de ellos consiste en que para poder llevar a cabo un control del gobierno es necesario que los votantes puedan asignar responsabilidades claras, lo que resulta menos factible si, por ejemplo, existe un gobierno de coalición o el partido del gobierno no es el mismo que cuenta con mayoría en el parlamento (Manin, Przeworski y Stokes, 1999: 47). Pero en la situación que estamos analizando resulta difícil atribuir responsabilidades únicas, tanto a nivel estatal como supraestatal.

Por un lado, dada la interconexión de los procesos políticos y, fundamentalmente, los económicos, la eficacia de las políticas públicas ya no es responsabilidad exclusiva del gobierno de un país ni una cuestión únicamente de gestión política. La consecuencia de todo ello es un "déficit de gobierno" (Zürn, 1994: 84), en cuanto que la globalización de los contextos de acción social y política en el ámbito de la economía, la seguridad, la ecología, ha reducido drásticamente el campo de acción de los gobiernos nacionales para solucionar problemas económicos, ecológicos y de seguridad.

Por otra parte, dado el sistema de constitución de la Comisión, es muy posible que el signo de la mayoría parlamentaria no coincida con el de la Comisión. La probabilidad de que esta situación se produzca es bastante alta ya que, como ha sucedido en estas últimas, las elecciones europeas suelen utilizarse como un mecanismo de sanción a los partidos que gobiernan en cada uno de los países, dando como resultado, en este caso, el triunfo del Partido

3 Ver el análisis de los programas de los partidos españoles en las últimas elecciones europeas en Montabes y Szmolka (2000).

4 Si la media de participación en las elecciones nacionales en Europa es de un 80,7 por 100, en las elecciones al Parlamento Europeo sólo alcanza el 58,6 por 100. 
Popular Europeo frente a la socialdemocracia gobernante en la mayoría de los países de Europa. La excepción se produce cuando se celebran inmediatamente después de las elecciones generales, caso en que los resultados suelen ser bastante semejantes porque el partido en el gobierno aún no ha tenido oportunidad de desgastarse.

De esta forma, los actuales procesos de integración provocan una situación paradójica. Nunca en la historia ha habido tantas personas que viven bajo gobiernos que pueden calificarse como democráticos. Por otro lado, el Estado ha ido aumentando en las funciones que se le consideran como propias y en la complejidad de su aparato burocrático. A pesar de ello, el poder real de los Estados está debilitándose, al compartirlo con las estructuras transnacionales emergentes. La práctica totalidad de los Estados dispone en los años noventa de capacidades mucho mayores que hace dos siglos, pero, ahora mismo, los políticos actúan en sus decisiones con restricciones al menos tan fuertes como en el pasado. La incidencia de las decisiones del Banco Mundial o del Consejo de Europa en la política económica de un país es con frecuencia mayor que la del propio gobierno. Por eso, aunque sea actualmente más alta la proporción de personas que participan en la selección democrática de los dirigentes nacionales, no resulta evidente que con ello tengan una capacidad efectiva de influir en las decisiones políticas capitales ni, por lo tanto, de controlar a quienes toman dichas decisiones.

De aquí podemos deducir que el "déficit democrático» de la Unión Europea es, fundamentalmente, un déficit de legitimidad. La legitimidad de un régimen político, de un gobierno, el apoyo de los ciudadanos, puede estar basada en los inputs que el sistema recibe, es decir, en el sentimiento que tengan los ciudadanos respecto a su capacidad real para hacer llegar sus demandas y participar en la formación de la voluntad política. Y puede basarse también en lo que el sistema produce, en los outputs, en la capacidad para satisfacer las demandas. La legitimidad de la Unión Europea es una legitimidad centrada en los outputs, en su aptitud para solucionar problemas que trascienden los límites del Estado nacional. Sería una legitimidad de carácter instrumental. Mientras los ciudadanos y los partidos de los países miembros de la Comunidad reconocieron que problemas que superan los límites del Estado exigen soluciones que también trascienden los límites del Estado, la integración europea se ha apoyado en una política considerada como legítima.

Pero la situación cambia con la constitución en 1979 de un parlamento elegido directamente por los ciudadanos. A partir de ahí se plantea la exigencia de que la política europea sea legitimada democráticamente mediante la participación de los ciudadanos en la formación de la voluntad política y por la elección directa de representantes. Cuando en 1991, con el Tratado de Maastricht, se da un paso decisivo en la unificación política, la legitimidad de la política europea se convierte en un problema fundamental, puesto que las instituciones europeas alcanzan una elevada dosis de poder político al aumentar considerablemente las competencias asumidas. $\mathrm{Y}$ es aquí, como hemos visto, 
donde se produce el déficit, en lo que entra en el sistema, en las posibilidades que los ciudadanos tienen de participar en la formación de la voluntad política y, consecuentemente, en el control de las decisiones.

En este sentido, la Unión Europea está siendo víctima de su propio éxito. Su crecimiento espectacular en número de Estados miembros y en los poderes que ejerce ha sido tan rápido que no ha podido crear nuevas vías para reforzar su legitimidad. El proceso de «desnacionalización» de la política, provocado por la globalización de los procesos económicos y sociales, sigue un ritmo bastante más rápido que el de la «desnacionalización» de las instituciones (Zürn, 1994). Lo que ocurre es que el modelo de democracia que se proyecta sobre Europa desde distintas disciplinas, como la Sociología, el Derecho, la Ciencia Política o la Economía, permanece muy ligado al Estado y a los elementos que lo definen, fundamentalmente el territorio y la nacionalidad. Y de este desajuste se derivan, como veremos, una serie de obstáculos para la democratización de la política más allá del Estado nacional; obstáculos que algunos autores consideran insalvables.

\section{2.b) De la concepción territorial a la concepción funcional de la ciudadanía}

Además de la soberanía y la legitimidad, esta situación altera también el concepto de ciudadanía entendida como pertenencia y como fuente de identidad que funda un contexto de solidaridad. El cambio fundamental, a mi modo de ver, es el paso de una solidaridad y una ciudadanía territorial a una solidaridad y una ciudadanía funcional.

Al hablar de una ciudadanía europea no se puede traspasar tal cual el modelo tradicional de democracia a un ámbito más amplio. Fundamentalmente, por dos razones. Por un lado, porque la teoría clásica de la democracia se ha basado en una homogeneidad, una perfecta correspondencia entre pueblo y estructuras políticas. Pero no existe algo semejante a un demos europeo. Y, por otro, porque tampoco existe una opinión pública y un espacio público europeos.

La identidad política en entidades como la Unión Europea no es fruto de un origen común. No existen los presupuestos imprescindibles para poder hablar de un pueblo europeo con una identidad cultural propia que pudiera fundar una comunidad política unitaria. Menos aún ante la progresiva ampliación de la Unión Europea hacia el Este. La «identidad» es resultado de un diseño institucional motivado por un interés compartido y, por lo tanto, con una orientación hacia el futuro, a diferencia de la nacionalidad, que hace referencia a un pasado común. Por eso, el sentido de pertenencia a una unidad política común y la capacidad de integración estará en función de los resultados de la política comunitaria, no de una comunidad cultural previamente existente. Esto es lo que se ha llamado "ciudadanía funcional» (Habermas, 1996) o "ciudadanía de mercado» (Marías, 1995). En este sentido, en la construcción de entidades políticas supraestatales ocurre algo semejante que en el Estado de Bienestar. La intervención estatal en la economía necesita lo que algunos auto- 
res, como Habermas y Offe, han denominado un "plus de legitimación», desde el momento en el que supone una cierta limitación de la libertad individual en lo económico. Por eso es especialmente importante que las políticas públicas emanadas del Estado de Bienestar sean eficaces en cuanto al crecimiento económico, la redistribución de los recursos y la provisión universal de servicios sociales de calidad. De la misma manera, la cesión relativa de la soberanía exigida por los procesos de integración requiere también un plus de legitimación. Resulta de vital importancia, entonces, la eficacia de las políticas europeas para que la limitación de la soberanía sea aceptada como legítima.

La legitimidad de la Unión Europea se basa en los intereses de los estados miembros, no en la voluntad de autodeterminación de un presunto pueblo europeo que políticamente no existe y ahora mismo nada hace pensar que pueda existir en el futuro (Grimm, 1995; Smith, 1991; Dahl, 1994). Se basa en el interés común a varios sujetos, no en los intereses de un único sujeto (Lübbe, 1994: 100). Esto se pone de manifiesto, por ejemplo, en la manera como se plantea la campaña electoral europea. Los temas recurrentes en la campaña hacen más referencia a la defensa en Europa de los intereses de cada uno de los Estados que a cuestiones ideológicas. Paralelamente, aunque los parlamentarios se unan en grupos en el Parlamento Europeo, el conflicto en la elaboración de las distintas políticas sectoriales gira en torno a los intereses de los diferentes países, más que sobre planteamientos ideológicos.

Se trata, entonces, de una identidad vaga, sin tradiciones, fundada en intereses, sobre todo, de carácter económico. La condición de «ciudadano europeo» está delimitada en términos de derechos, los derechos de corte liberal definidos en Maastricht. Pero es una ciudadanía y una fuente, por tanto, de legitimidad de las decisiones políticas sumamente débil, debido a la ausencia de los aspectos no jurídicos en los que debería basarse su construcción: no se deriva de una identidad cultural, sino de un comunidad de intereses.

Y, hoy por hoy, resulta bastante cuestionable que esa legitimidad puramente pragmática sea suficiente para fundar lazos fuertes de solidaridad. Es conocida la postura de Habermas (1996) a este respecto, que propone que el "patriotismo constitucional» basta para constituir una fuente de solidaridad y legitimidad de las nuevas estructuras de poder, junto con la experiencia histórica común a los países europeos, que ha hecho ver la necesidad de superar el nacionalismo, y que no se requiere la existencia de un pueblo homogéneo para garantizar la integración y la legitimidad ${ }^{5}$. En una línea semejante se situaría la

En su opinión, no constituyen un contraargumento los conflictos surgidos en los Estados artificialmente formados tras la descolonización. Estos países querían obtener una soberanía externa sin disponer al mismo tiempo de un poder estatal efectivo y la soberanía interna se alcanzó con muchas dificultades, ya que el problema era llenar de contenido nacional estructuras estatales previamente existentes. Los conflictos étnicos que han aparecido en estos países ponen de manifiesto que las naciones solamente surgen cuando se ha logrado transformar la comunidad de los que pertenecen a una misma etnia, de aquellos que no son ajenos entre sí, en una solidaridad mediada por el derecho entre ciudadanos que frecuentemente son extraños entre ellos. 
tesis de Przeworski (1999), que considera que son las instituciones las que crean los incentivos para la participación y la legitimidad. Pero las estructuras resultantes de los procesos de integración son una fuente muy precaria de identidad. Prueba de ello es el resurgir de los movimientos nacionales en la actualidad. Esto es así porque, como señala Guéhenno, "donde no hay delimitación de un territorio, hay búsqueda de los orígenes; si no te defines por el lugar en el que vives, dime de dónde vienes» (Guéhenno, 1995: 52).

De aquí se deriva otra de las dificultades para la construcción de una democracia europea. Un elemento clave de la democracia es la idea de igualdad entre los ciudadanos en cuanto a sus derechos. Con la transformación del Estado liberal en un Estado democrático-liberal primero y después en un Estado social, la condición de ciudadano viene definida por una serie de derechos civiles, políticos y sociales que el Estado debe garantizar. Estos últimos exigen que el Estado lleve a cabo una redistribución de los bienes mediante cargas impositivas con el fin de garantizar unas rentas mínimas y recaudar fondos necesarios para proveer a la población de los servicios sociales básicos. Pero el sentimiento de identidad europea no es lo suficientemente fuerte como para crear un sentimiento de solidaridad que justifique la intervención estatal. No resulta fácil que las políticas redistributivas cuenten con la legitimación de los países o las clases de renta más alta, cuando el resultado de esa redistribución va a ir a parar a unos individuos que viven a miles de kilómetros de distancia y con los que los lazos de unión son muy débiles. Y es que la identidad común constituye un presupuesto de la solidaridad (Miller, 1997; Smith, 1991). De hecho, salvo en lo que se refiere a la agricultura, aún no se ha desarrollado un acuerdo que estipule una redistribución de fondos entre fronteras territoriales y de clase. Por otra parte, la propia idea de redistribución resulta difícil de armonizar con una ciudadanía basada no en un origen y una identidad comunes, sino, sobre todo, en un interés común. Si es el interés lo que funda la solidaridad, no tiene mucho sentido recurrir después a la solidaridad para recortar el propio interés. No hay, por lo tanto, un demos transnacional, sino una pluralidad de demos transnacionales. Y esto constituye una seria dificultad para el desarrollo de un Estado de Bienestar en Europa.

La otra dificultad para poder hablar de un demos europeo es la inexistencia de un espacio público, de una opinión pública común (Schmitter, 1996). Toda comunidad política necesita un espacio propio como horizonte de significado de los procesos de comunicación que tienen lugar en ella. Ese espacio político no se identifica con el territorio ni con la publicidad institucionalizada, sino que constituye su presupuesto. Cuando la comunidad política trasciende las fronteras, conectando diferentes espacios políticos, surgen problemas de traducción, porque la traducción verbal no implica necesariamente una traducción adecuada de significados. Un ejemplo muchas veces repetido es que el término "autoritarismo» no significa lo mismo para un alemán que para un inglés. En ello juega un papel muy importante la historia y las experiencias vividas por cada una de las comunidades. 
Por otro lado, y estrechamente relacionado con lo que acabo de señalar, tampoco existe una opinión pública europea (Albromeit/Schmidt, 1998). La accesibilidad y la posibilidad de participar en la comunicación política constituye un presupuesto del sistema democrático. Todos los afectados por una decisión tendrían que poder formar parte del público. Pero las diferencias idiomáticas suponen hoy por hoy un obstáculo para la formación de una opinión pública europea no muy fácil de salvar. Prueba de ello es que en los medios de comunicación de ámbito europeo hay, sobre todo, retransmisiones de «espectáculos», de «imágenes», más que de información. Habría, por tanto, una gran cantidad de excluidos de ese espacio público europeo.

Además, hay que tener en cuenta el elevado coste de la información sobre las cuestiones de política europea. "Los ciudadanos — afirma Dahl— deberían estar tan preocupados en informarse sobre las decisiones políticas de las organizaciones internacionales como hoy lo están respecto de las decisiones públicas en sus propios países» (Dahl, 1999: 134). Pero, dada la complejidad de los procesos de decisión, obtener información suficiente sobre la política europea, sobre el funcionamiento de sus instituciones, supondría para los ciudadanos una carga aún mayor que lograr una información adecuada acerca de los diferentes aspectos de política nacional. El coste es mucho mayor que los beneficios que pueden obtener. Esto explica, por poner un ejemplo, que hasta finales de 1998 sólo un 51 por 100 de los españoles habían oído hablar del Parlamento Europeo ${ }^{6}$.

En conclusión, el déficit democrático no es sólo de carácter institucional sino, sobre todo, socioestructural. Para solucionar el problema no basta con cambiar las instituciones. Sin embargo, la mayor parte de las propuestas de una mayor democratización de la Unión Europea van en la línea de las reformas institucionales.

\section{PRINCIPALES PROPUESTAS PARA SUPERAR EL DÉFICIT DE REPRESENTACIÓN EN EUROPA}

El problema de la "superación del cisma entre integración y democracia» (Joerges/Neyer, 1997: 230) ha recibido respuestas diferentes, dependiendo de cuál se considere el núcleo del problema de la carencia democrática. Las distintas propuestas de una forma de representación política adecuada a una Europa integrada pueden dividirse entre las que abogan por su parlamentarización y las que, al considerarla imposible, optan por un sistema federal-descentralizado. En este segundo grupo pueden distinguirse, a su vez, propuestas que apuntan hacia una democracia consociacional o "postparlamentaria" y las que proponen incorporar formas propias de una democracia directa.

Está bastante claro que el Parlamento Europeo no satisface las normas de

${ }^{6}$ Sondeo del Instituto Louis Harris, El País, 30 de mayo de 1999. 
una democracia parlamentaria; es insuficiente como institución representativa. Se critica, como hemos visto, el procedimiento de elección, que se rige por reglas diferentes en cada país y que está controlado por partidos nacionales al no existir partidos políticos europeos que pudieran presentar candidaturas en todas las circunscripciones. Además, los partidos se unen en grupos en el Parlamento según familias ideológicas, pero son grupos con una gran falta de cohesión. Si existiera un sistema de partidos europeo y una circunscripción única, regido por un único sistema electoral (cuya posibilidad contempla el Tratado de Amsterdam), se solucionarían, en parte, las dificultades. Pero, sobre todo, el núcleo del problema lo constituye el hecho de que el Parlamento Europeo únicamente tiene, como mucho, el poder de codecisión, mientras que las competencias legislativas residen en el Consejo de Ministros. Las facultades de control del Parlamento a la Comisión son también insuficientes, aunque las sucesivas reformas institucionales desde el Acta Única hasta el Tratado de Amsterdam han tratado de reforzar en este sentido los poderes del Parlamento.

Hacia una parlamentarización de la política europea apunta también la propuesta de Held. Diseña un "modelo federal de autonomía democrática» (1995), basado en un cambio en las fronteras territoriales de los sistemas de responsabilidad, de forma que las cuestiones que escapan al control del Estado nacional puedan estar mejor controladas. Para ello, es preciso articular los sistemas políticos territorialmente delimitados con las estructuras internacionales, de forma que éstas pasen a formar parte de un proceso democrático. Los medios fundamentales para ello son, en opinión de Held, básicamente dos. En primer lugar, realzar el papel del Parlamento Europeo, de manera que pueda ser reconocido como fuente legítima de Derecho internacional y hacerlo más accesible al control y participación de los ciudadanos. Además, habría que limitar el poder de las corporaciones multinacionales, movidas por intereses económicos, no siempre de carácter democrático, para influir en la agenda política. La política europea debería girar, por tanto, en torno a la centralidad del Parlamento Europeo, articulado con los Parlamentos nacionales.

Al fortalecimiento de los mecanismos que permitan un mayor control de los ciudadanos sobre la política comunitaria, Robert Dahl añade la necesidad de compensar la ampliación del ámbito de las decisiones políticas vinculantes con el aumento de las posibilidades de un control efectivo en comunidades inferiores al Estado nacional sobre cuestiones que afectan directamente a sus vidas, como la educación, la salud pública o la ordenación urbana (Dahl, 1994: 33).

La propuesta que apunta a la vía de la parlamentarización no es aceptada por aquellos autores cuya crítica a la democraticidad de la política europea se basa en la consideración de sus presupuestos sociales (Kielmansegg, 1996; Zürn, 1996). Las decisiones tomadas en una democracia parlamentaria a partir del criterio de la mayoría sólo estarían justificadas si la sociedad formara una comunidad política, con una tradición común y con un espacio único de comunicación. Pero esto exigiría una cultura y una lengua comunes. Por lo 
tanto, no es posible la legitimidad de una democracia parlamentaria que estaría provocando una exclusión de carácter estructural. Dada la diversidad de identidades nacionales, fuertemente arraigadas en cada uno de los Estados europeos, sean mononacionales o no, no parece muy viable la instauración de una lógica unitaria. El sistema institucional debe descansar, entonces, sobre la base de que la fuente de su legitimidad se encuentra en cada uno de los Estados que lo constituyen; no en los ciudadanos, como si éstos formaran una comunidad política unitaria, sino en cada una de las comunidades políticas de los Estados miembros. Según estos autores, la representación sólo puede realizarse, entonces, en dos fases: los ciudadanos europeos son representados directamente en los parlamentos nacionales que, a su vez, envían representantes de los países a las instituciones europeas. Por ello, la legitimación democrática sólo puede realizarse mediante un orden federal en el cual los parlamentos nacionales dispongan de un amplio margen de autonomía (Scharpf, 1998).

Algunos autores han objetado que la existencia de un idioma común no constituye un requisito imprescindible para que pueda hablarse de una comunidad política; la sociedad civil también puede formarse a partir de la pluralidad emergente de organizaciones con intereses comunes. Por otro lado, la democracia parlamentaria no sólo resulta problemática a nivel europeo, sino también dentro de los límites del Estado nacional. Lo que está surgiendo a todos los niveles es una "democracia postparlamentaria» (Andersen/Burns, 1998), una "democracia asociativa» (Schmalz-Bruns, 1997), un "neocorporativismo» (Schmitter), que viene a completar o incluso a sustituir a las formas territoriales de representación política. Aumentar, sin más, la capacidad de los parlamentos nacionales para controlar lo que sucede en Europa no es suficiente, dada la carencia de autonomía decisoria que éstos sufren en la actualidad en el ámbito de cada uno de los Estados. Por ello, el medio para democratizar la política europea será impulsar las distintas formas de representación de los intereses de los ciudadanos, fundamentalmente las formas de representación corporativa. Ésta es la propuesta de Schmitter: una combinación de formas de representación territoriales con formas funcionales que configurarían un orden político estable peculiar, no estatal y tampoco nacional, que no se asemejaría ni a una organización intergubernamental ni a un Estado nacional (Schmitter 1996).

Sin embargo, los procesos de negociación y decisión en esas redes corporativas son, igualmente, muy poco transparentes y, en ocasiones, lejanos a la mayoría de los ciudadanos. Por ello, más que la solución, sería una causa más del déficit democrático de la Unión Europea. Por ello, se aboga por la introducción de prácticas de la democracia directa, en concreto el recurso al referéndum (Zürn, 1996) y la elección directa del Consejo de Ministros y la Comisión. Pero este planteamiento no da cuenta de si unas estructuras políticas como las actuales, poco transparentes y lejanas a los ciudadanos, son el presupuesto más adecuado para una democracia directa o si, más bien, habría que crear primero unas condiciones de transparencia y cercanía para hacerla posible. 
Las diferentes propuestas surgen de fijar la atención en distintos aspectos del problema. Por eso, lo más probable parece una constitución mixta que combine elementos de la democracia representativa, tanto territorial como funcional, con una división efectiva de poderes tanto horizontal como vertical.

La consecuencia es, por supuesto, que el déficit de representación sólo puede ser superado a costa de disminuir la eficiencia del gobierno, entendida como la proporción entre el coste y la calidad de la decisión. El coste de la decisión, que depende sobre todo de la cantidad de tiempo que es necesario invertir, aumenta con el número de actores, de instituciones implicadas, de votos afirmativos exigidos para tomar una decisión y la divergencia de intereses. La calidad de las decisiones depende de la relación entre lo esperado y lo realizado.

Con el fin de superar el déficit de legitimación se ha propuesto, como hemos visto, un fortalecimiento del parlamento en los diferentes niveles de gobierno de la Unión Europea para aumentar así la transparencia y la capacidad de control. Pero esta vía de reforma amenaza la eficiencia del gobierno. Por un lado, porque aumentarían las posibilidades de bloqueo y, por otro, porque los representantes de los gobiernos nacionales estarían mucho más fuertemente atados a las directrices políticas y al control de sus respectivos parlamentos. Resultaría, por tanto, más difícil llegar a posiciones de consenso.

Si se refuerzan las formas no parlamentarias de mediación de intereses y se consideran como una vía legítima de representación democrática y se institucionalizan como tales, darían lugar a estructuras de decisión mixtas —representantes de los gobiernos/representantes de las asociaciones- de carácter sectorial. Sin embargo, esta propuesta puede tener también consecuencias no deseadas para la toma de decisiones. Por una parte, porque se darían intereses o divisiones "cruzadas» al combinar una representación territorial con una representación funcional, lo cual aumentaría las posibilidades de conflicto. Éstas serían aún mayores si se introduce la exigencia de una legitimación de la política europea por los parlamentos nacionales. Además, propiciaría, por un lado, una atención selectiva a las demandas y, por otro, una consideración de los intereses particulares, por encima de los intereses generales representados por los gobiernos. Y el problema fundamental radica en las posibilidades de bloqueo en las negociaciones, precisamente por la primacía concedida a intereses sectoriales frente a los estatales.

En definitiva, lo que aquí está en juego es el dilema al que apunta Robert Dahl (1994) y que se presenta también en muchas otras decisiones de diseño institucional: la capacidad de los ciudadanos para hacer llegar las demandas y ejercer un control democrático sobre las decisiones políticas frente a la aptitud del sistema para responder de manera satisfactoria a las preferencias colectivas de los ciudadanos. En otras palabras, optar por una mayor representatividad o por una mayor eficacia del gobierno. 


\section{CONCLUSIÓN}

De todo esto podemos deducir que el déficit democrático de la Unión Europea es un problema complejo que requiere también una solución compleja. El déficit resulta de una combinación de factores institucionales y otros de carácter socioestructural. Por lo que se refiere a lo institucional, ni la ampliación de competencias del Parlamento Europeo, ni el fortalecimiento de los parlamentos nacionales, ni el desarrollo de estructuras de una democracia asociativa son adecuados por sí solos para garantizar la legitimación democrática. Además, una democratización simultánea y equilibrada de las diferentes estructuras de representación amenaza con reducir la eficiencia al aumentar el coste de las decisiones y la posibilidad de conflicto. Por eso, lo que hay que buscar es estrategias de democratización que, junto a las relaciones "verticales» entre representantes y representados, a través de los distintos niveles de gobierno, articulen también la influencia "horizontal» entre las distintas formas de representación. La democratización de la Unión Europea tiene que contar, por tanto, con el hecho de que nos encontramos ante un sistema con una pluralidad de planos y competencias. El gobierno democrático de la Unión Europea debe ser concebido, entonces, como un «sistema de redes», formado a partir de una dualidad de sistemas de representación: la representación parlamentaria tradicional combinada con una representación de intereses de carácter sectorial, articulado en múltiples niveles, local, regional supranacional.

La cuestión institucional podría solucionarse a un plazo medio-largo, siempre que se tenga en cuenta esa pluralidad de ámbitos de competencia y representación, creando formas adecuadas de responsabilidad de los gobernantes y, al mismo tiempo, nuevos canales de representación tanto territorial como funcional. La política europea deberá apoyarse en los organismos y agencias comunitarias, en las instituciones de los Estados miembros, pero también en las organizaciones y grupos de interés. Es cierto que en los últimos años se ha avanzado bastante en esta línea. Pero existe un problema más profundo y de más difícil solución, que consiste en que si las decisiones políticas han de ser aceptadas por todos, incluso por los perdedores en el juego democrático, la ausencia de una identidad común seguirá constituyendo una fuente de tensiones. Y, tal y como nos muestra la historia política reciente, éste es un escollo de difícil solución. Se trata, entonces, de una situación semejante a aquella a la que da respuesta el Estado nacional: la necesidad de buscar una nueva fuente de legitimación y de integración social y política. Y la cuestión que, en último término, está aquí en juego, en el dilema entre democracia e integración, es hasta qué punto es válido el requisito para la construcción de un sistema democrático de una identidad previa que dote de legitimidad a las instituciones políticas y a las decisiones que de ellas emanen. 


\section{BIBLIOGRAFÍA}

Albromeit, H./Schmidt, Th. (1998): "Grenzprobleme der Demokratie», en B. Kohler-Koch, Regieren in entgrenzten Raumen, pp. 293-320.

Andersen, Svein S./Burns, Tom R. (1996): «The European Union and the erosion of Parliamentary Democracy: A study of post-parliamentary governance», en S. S. Andersen/K. A. Eliassen (eds.), The European Union. How democratic is it?, Sage, Londres, pp. 227-251.

BeCK, U. (1994): «Renaissance des Politischen oder Widersprüche des Konservatismus», en C. Leggewie, Wozu Politikwissenschaft? Uber das Neue in der Politik, Wissenschaftliche Buchgesellschaft, Darmstadt, pp. 34-46.

- (1997): Was ist Globalisierung?, Suhrkamp, Frankfurt a. M.

Canel, M. J./Innerarity, C. (2000): «La campaña electoral en la televisión», en A. Martínez y M. Méndez (eds.), Las elecciones al Parlamento Europeo, 1999, Tirant lo Blanch, Valencia, pp. 171-190.

DAHL, R. (1989): Democracy and its critics, Yale University Press, New Haven.

- (1994): «A democratic dilemma: System effectiveness versus citizen participation", en Political Science Quarterly, vol. 109, núm. 1, pp. 23-34.

- (1999): La democracia. Una guía para los ciudadanos, Taurus, Madrid.

Grimm, D. (1995): «Does Europe need a constitution?», en European Law Journal, 1, 3.

GuéHenno, J. M. (1995): El fin de la democracia. La crisis política y las nuevas reglas del juego, Paidós, Barcelona.

Habermas, J. (1996): Die Einbeziehung des Anderen, Suhrkamp, Frankfurt a. M.

Held, D. (1995): Democracy and the global order. From the modern state to cosmopolitan governance, Polity Press, Londres.

Joerges, Ch./NEYer, J. (1997): «From intergovernmental bargaining to deliberative political processes. The constitutionalisation of comitology», en European Law Journal, 3, 3, pp. 273-299.

Keohane, R. (1995): "Hobbes' dilemma and institutional change in world politics: sovereignty in international society», en H. Holm/G. Sorensen (eds.), Whose World Order, Boulder, Londres.

KielgmansegG, P. G. (1996): «Integration und Demokratie», en M. Jachtenfuchs/B. KohlerKoch (eds.), Europäische Integration, Westdeutscher Verlag, Opladen.

Kohler-Koch, B. (1998) (ed.): Regieren in entgrenzten Raumen, Westdeutscher Verlag, Opladen.

Leggewie, C. (ed.) (1994): Wozu Politik Wissenschaft? Uber das Neue in der Politik, Wissenschaftliche Buchgesellschaft, Darmstadt.

LÜвBE, H. (1994): Abschied vom Superstaat. Vereignite Staaten von Europa wird es nicht geben, Siedler, Berlín.

Manin, B.; PrZeworski, A., y Stokes, S. (1999): «Elections and representation», en A. Przeworski, S. Stokes y B. Manin (eds.), Democracy, Accountability and Representation, Cambridge University Press, Nueva York, pp. 29-54.

Markoff, J. (1998): Olas de democracia. Movimientos sociales y cambio politico, Tecnos, Madrid.

MARÍAS, E. (1995): European citizenship, European Institute of Public Administration, Maastricht.

Miller, D. (1997): On nationality, Oxford University Press, Oxford.

Montabes, J., y SzmolKa, I. (2000): «Los programas electorales», en A. Martínez y M. Méndez (eds.), Las elecciones al Parlamento Europeo, 1999, Tirant lo Blanch, Valencia, pp. 91147.

Przeworski, A.; Stokes, S. C., y Manin, B. (1999): Democracy, accountability and representation, Cambridge University Press.

ReIF, K. (1985): "The second-order national elections», en K. Reif (ed.), Ten European Elections, Aldershot, Gorver, pp. 1-36.

SCHARPF, Fritz W. (1998): "Demokratische Politik in der internationalisierten Ökonomie», en M. Th. Greven (ed.), Demokratie. Eine Kultur des Westens?, Leske und Budrich, Opladen, pp. 81-103. 
Schmalz-Bruns, R. (1997): «Bürgergesellschaftliche Politik. Ein Modell der Demokratisierung der Europäischen Union», en K. D. Wolf (ed.), Projekt Europa im Übergang, Nomos, BadenBaden, pp. 63-89.

SChmitter, Ph., y Karl, T. (1991): "What is democracy and is not», en Journal of Democracy, 2, pp. 175-191.

SChmitter, Ph. (1996): "Cómo debería democratizarse la Unión Europea y por qué: algunas reflexiones», en A Distancia. Revista de la UNED, otoño, pp. 129- 140.

- (1997): «Ist it really possible to democratize the Euro-polity?», en A. Follesdal y P. Koslowski (eds.), Democracy and the European Union, Berlín, pp. 13-36.

SmITH, A. (1979): Nationalism in the Twentieth Century, Oxford University Press, Oxford.

- (1991): National Identity, Sage, Londres.

ZÜRN, M. (1996): «Über den Staat und die Demokratie im europäischen Mehrebenensystem», en Politische Vierteljahresschrift, 37, pp. 27-55.

\begin{abstract}
This article analyses the way in which the present-day weakening of state frontiers affects the democratic system and political representation in particular, in its dual dimension of the channelling of demands and responsibility before all citizens. It specifically explains what the socalled «democratic deficit» of the European integration process consists of. It closes by offering a critical view of the different proposals made from the areas of sociology and political science for overcoming the democratic deficiencies of the process.
\end{abstract}

